\title{
The Interaction of Refractory Oxide with Matte
}

\author{
T. Ramakobya, BM Thethwayo and Antoine F. Mulaba - Bafubiandi
}

\begin{abstract}
Magnesia-Chrome bricks are used as the protective refractory lining and in the matte tap holes of the PGM smelters. Penetration of matte through the magnesia-chrome brick has been observed, by simulation, it was reported that up to 4 wt. \% refractory can dissolve in matte. Current work focuses on studying the mechanism responsible for the matte refractory interaction. The matte specie $(\mathrm{FeS})$ will be reacted with synthetic refractory oxides $\left(\mathrm{Cr}_{2} \mathrm{O}_{3}\right.$ and $\left.\mathrm{Fe} / \mathrm{MgCr}_{2} \mathrm{O}_{4}\right)$ to determine the mechanism of interaction through the analysis of the residual products. A pressed pellet each made of $(\mathrm{FeS}+\mathrm{Cr} 2 \mathrm{O} 3)$ or $\left(\mathrm{FeS}+\mathrm{Fe} / \mathrm{MgCr}_{2} \mathrm{O}_{4}\right)$ will be heated to $1200^{\circ} \mathrm{C}, 1350$ ${ }^{\circ} \mathrm{C}$ and $1500^{\circ} \mathrm{C}$. The residue will be analyzed with the SEM_BSE and EDS. It is anticipated that FeS will react with the oxides forming $\mathrm{Fe}$ $(\mathrm{Mg}, \mathrm{Cr}) \mathrm{S}$, and an oxy-sulfide. The dissolution of the oxides in the sulfide will possibly affect the composition and the melting temperature of the sulfide.
\end{abstract}

Keywords - PGM refining, Refractory bricks, matte penetration, PGM concentrates.

\section{INTRODUCTION}

The key part of metallurgical process that recognize Platinum Group Metals (PGM) concentrates refining from that of other base metal sulfide concentrates are displayed. The distinction incorporate extensively higher input chromite and manganese substance that specifically raise the slag liquidus temperature and can possibly expand collections of refractory spinels. In particular, the higher smelting temperature required for PGM melting, and that results to higher matte superheat than matte temperatures of other common refining operations (Eksteen, 2009), thus this tends to damage the furnace refractories.

High matte superheat is a challenge in the furnace operation of PGM melting as the product is being contaminated and furnace breakout rate increases. Refractories must be capable of maintaining good physical, chemical and thermal properties at very high temperatures. The typical refractories are used as lining in PGM smelters, essentially chrome-magnetite and magnesia-chrome and Alumina-Chrome (Lange et al, 2014).

Investigation concerning the understanding of the causes of the refractory materials breaking down in the furnace will be conducted. Penetration of slag, matte, and gases through refractory is observed at typical operating temperatures, dissolutions have also been observed which results to corrosion and erosion of the furnace lining. Temperatures above $1500^{\circ} \mathrm{C}$ are conducive for sulfidising $\mathrm{Cr} 2 \mathrm{O} 4$ or $\mathrm{Fe} / \mathrm{MgCr} 2 \mathrm{O} 4$ refractory

T. Ramakobya, BM Thethwayo and Antoine F. Mulaba - Bafubiandi, University of Johannesburg, Mineral processing and technology research centre, Department of metallurgy, School of mining, metallurgy and chemical engineering, faculty of engineering and the built environment, P.O. Box 17011 Doornfontein, 2028, Johannesburg, South Africa by matte. In order to consider the furnace operating temperatures, the important parameter is how to control chromium in the system which is achieved by setting up optimum furnace temperatures (Jacobs, 2006).

Concerning the high temperatures when smelting concentrates containing high chromite content can damage the defensive freeze lining of the slag when matte temperature is higher than liquidus temperature of slag (Eksteen, 2011). Matte temperature ranging from $1400{ }^{\circ} \mathrm{C}$ to $1500{ }^{\circ} \mathrm{C}$ and the slag temperature of $1600{ }^{\circ} \mathrm{C}$ to $1700{ }^{\circ} \mathrm{C}$ were predicted by Synders (2006). The above high operating temperatures favors the penetration of matte into the furnace refractories.

From the work and thermodynamics calculations done by Eksteen(2011), the estimated that at temperatures greater than $1500{ }^{\circ} \mathrm{C}$ the matte has tendency of reacting with the refractory lining of the furnace. This will result in the presence of chromium reporting in the matte together with the oxygen from the refractory as explained by the following equations:

Equation 1

$(\mathrm{FeCr} 2 \mathrm{O} 4)$ refractory $+2[\mathrm{~S}]$ matte $+3[\mathrm{Fe}]$ matte $=2[\mathrm{CrS}]$ matte $+4[\mathrm{FeO}]$ matte

With $\Delta \mathrm{G}^{\circ}=-8.478 \mathrm{KJ} / \mathrm{mol}$ at $\mathrm{T}=1500{ }^{\circ} \mathrm{C}\left(\Delta \mathrm{G}^{\circ}<0\right.$, when $\mathrm{T}>$ $\left.1450{ }^{\circ} \mathrm{C}\right)$

\section{Equation 2}

$(\mathrm{MgCr} 2 \mathrm{O} 4)$ refractory $+2[\mathrm{~S}]$ matte $+3[\mathrm{Fe}]$ matte $=2[\mathrm{CrS}]$ matte $+3[\mathrm{FeO}]$ matte $+(\mathrm{MgO})$ refractory

With $\Delta \mathrm{G}^{\circ}=+11.03 \mathrm{KJ} / \mathrm{mol}$ at $\mathrm{T}=1500{ }^{\circ} \mathrm{C}\left(\Delta \mathrm{G}^{\circ}<0\right.$, when $\mathrm{T}>$ $\left.1650^{\circ} \mathrm{C}\right)$.

\section{MATERIALS}

In this project synthetic matte which is the sulphide (FeS) powder is used together with chromium oxide ( $\mathrm{Cr} 2 \mathrm{O} 3)$, and industrial chromite $(\mathrm{Fe} / \mathrm{MgCr} 2 \mathrm{O} 4)$ as a formula representing refractory material. To check the penetration of matte in the refractory, SEM analysis will be utilized and XRD for matte and refractory crystalline phase composition analysis.

- Graphite crucible

- Tube Furnace (horizontal)

- SEM, XRF \& XRD equipment

- Thermocouple

- Pelletizer machine

- Pulverize machine

\section{EXPERIMENTAL}

Laboratory-scale tests were conducted to simulate the magnesia-chrome brick and matte interaction. The graphite 
crucible was used and argon gas was purged into a furnace to prevent sulphur in $\mathrm{FeS}$ to oxidize. FeS powder was mixed with the grind $\mathrm{Cr}_{2} \mathrm{O}_{3}$ or $\mathrm{Mg} / \mathrm{FeCr}_{2} \mathrm{O}_{4}$ refractory to make a pressed pellet. The pressed pellet was exposed to $1200{ }^{\circ} \mathrm{C}, 1350{ }^{\circ} \mathrm{C}$ and $1500{ }^{\circ} \mathrm{C}$ for 1 hour. The temperature profile of the tube furnace was established and the temperature reading on the controller was verified by thermocouple. The furnace heating and cooling rate was $10^{\circ} \mathrm{C}$ per min. Figure 1 and 2 are the SEM images of the samples before being exposed to heat.

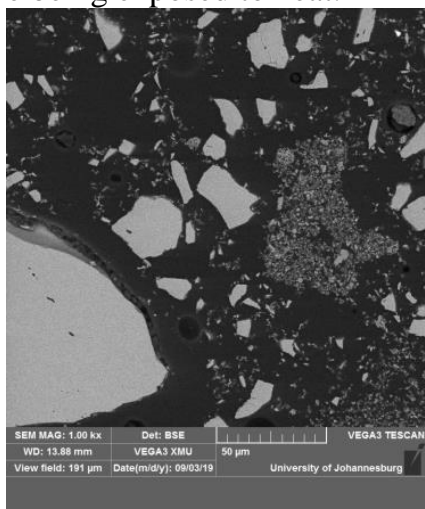

Fig 1: Scanning Electron Microscope images of before $\left[\mathrm{FeS}+\mathrm{Cr}_{2} \mathrm{O}_{3}\right.$ recipe]

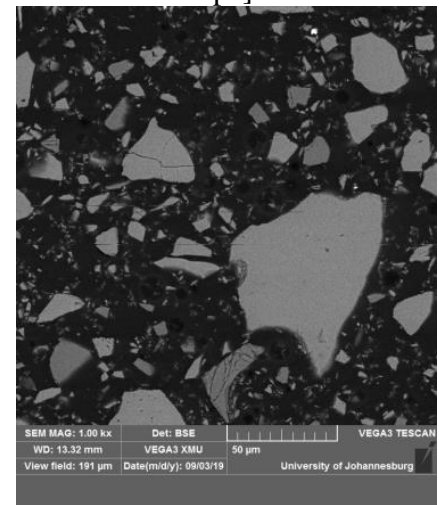

Fig 2 : Scanning Electron Microscope images of before $\left[\mathrm{FeS}+\mathrm{FeMgCr}_{2} \mathrm{O}_{4}\right.$ recipe $]$

\section{RESULTS AND DISCUSSION}

The interaction of $\mathrm{FeS}$ to $\mathrm{Cr}_{2} \mathrm{O}_{3}$ and $\mathrm{FeCr}_{2} \mathrm{O}_{4}$ was limited as there are spaces been them. As temperature reaching the melting point of $\mathrm{FeS}$ which is $1194{ }^{\circ} \mathrm{C}$ there is a clear indication of crystals being in contact with one another. It is very critical to study the analysis of refractory and matte interface as it would represent the actual reaction in the furnace as the lining would be in contact with the heated matte. The melting temperature of chromium oxide and industrial chromite is been lowered when it is exposed to FeS. The mineral that is used is pyrite with more of sulphur wt $\%$ to less of iron amount. When this pyrite is heated to temperatures above $200{ }^{\circ} \mathrm{C}$, the sulphur is given off which leave a residue of iron(ll) sulfide

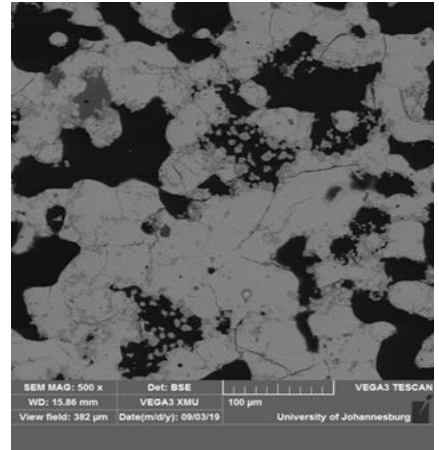

Fig 3: Scanning Electron Microscope images at $1200^{\circ} \mathrm{C}$ $\left[\mathrm{FeS}+\mathrm{Cr}_{2} \mathrm{O}_{3}\right.$ recipe $]$.

From table 1, it shows that spectrum 1 and 3 are similar phase of iron sulfide with 9 wt $\% \mathrm{Cr}$. The new phase has evolved which contains $50 \%$ oxygen and it is also enriched with sulphur and iron. It is observed that, on the periphery of surrounded crystals the shape is smooth which shows that the material reached its melting point.

TABLE 1: SEM -BSE RESULTS AFTER EXPOSER AT $1200{ }^{\circ} \mathrm{C}\left[\mathrm{FES}+\mathrm{CR}_{2} \mathrm{O}_{3}\right.$ RECIPE]

\begin{tabular}{|l|c|c|c|c|c|}
\hline \multicolumn{7}{|c|}{$1200^{\circ} \mathrm{C}$} \\
\hline Mass \% & $\mathrm{FeS}$ & $\mathrm{Cr}_{2} \mathrm{O}_{\mathbf{3}}$ & $\mathbf{1}$ & $\mathbf{2}$ & $\mathbf{3}$ \\
\hline $\mathrm{O} \mathrm{K}$ & 0 & 50 & 0 & 13 & 0 \\
$\mathrm{CrK}$ & 1 & 50 & 8 & 11 & 9 \\
$\mathrm{Fe}$ & 46 & 0 & 46 & 39 & 46 \\
$\mathrm{SK}$ & 53 & 0 & 47 & 37 & 44 \\
\hline
\end{tabular}

Fig 4 : Scanning Electron Microscope images of at $1200^{\circ} \mathrm{C}$ $\left[\mathrm{FeS}+\mathrm{FeMgCr}_{2} \mathrm{O}_{4}\right.$ recipe]

At 1200, there is a clear indication that gases are emitted with the trace of the black spaces in figure 4. Iron sulfide in this recipe has less than $9 \%$ similar to the phases in figure 3 . From table 2, the new phase which is present is an oxide reach in $\mathrm{Cr}$ of $43 \mathrm{wt} \%$. There is also a residual phase of the original composition which did not react. The periphery of surrounded crystals shows that the melting point was not reached because of rough surface. 
TABLE II: SEM -BSE RESULTS AFTER EXPOSER AT $1200^{\circ} \mathrm{C}(\mathrm{FES}+\mathrm{FEMGCR} 2 \mathrm{O} 4$ SAMPLE).

\begin{tabular}{|l|c|c|c|c|c|}
\hline \multicolumn{6}{|c|}{$1200^{\circ} \mathrm{C}$} \\
\hline Mass \% & FeS & $\left(\right.$ FeMgAl) $\mathrm{Cr}_{2} \mathrm{O}_{4}$ & 1 & 2 & 3 \\
\hline $\mathrm{O} \mathrm{K}$ & $\mathbf{0}$ & 42 & 0 & 9 & 40 \\
$\mathrm{Al} \mathrm{K}$ & $\mathbf{0}$ & 10 & 0 & 16 & 10 \\
Cr K & $\mathbf{1}$ & 25 & $\mathbf{2}$ & 43 & 26 \\
Fe K & $\mathbf{4 6}$ & 15 & $\mathbf{4 9}$ & 19 & 16 \\
Mg K & $\mathbf{0}$ & 8 & $\mathbf{0}$ & 12 & 7 \\
S k & $\mathbf{5 3}$ & 0 & $\mathbf{4 9}$ & 0 & 0 \\
\hline
\end{tabular}

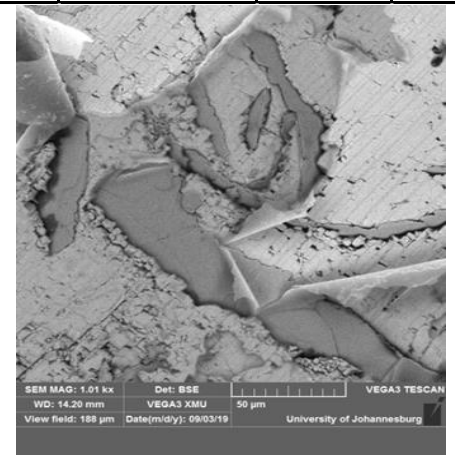

Fig 5 : Scanning Electron Microscope images at $1350^{\circ} \mathrm{C}\left(\mathrm{FeS}+\mathrm{Cr}_{2} \mathrm{O}_{3}\right.$ recipe)

At $1350{ }^{\circ} \mathrm{C}$, there is still a phase which was present before at $1200{ }^{\circ} \mathrm{C}$ which contained about $9 \mathrm{wt} \% \mathrm{Cr}$ with iron sulfide. From table 3 , it can be observed that the residual phase is no longer found but new phase is formed containing $\mathrm{Cr}, \mathrm{S}, \mathrm{Fe}$ and $\mathrm{O}$. There is also a new phase which contains mostly elemental sulfur and iron with chromium.

TABLE 2: SEM -BSE RESULTS AFTER EXPOSER AT $1200{ }^{\circ} \mathrm{C}\left(\mathrm{FES}+\mathrm{CR}_{2} \mathrm{O}_{3}\right.$

\begin{tabular}{|c|c|c|c|c|c|c|c|}
\hline \multirow[b]{3}{*}{ Mass \% } & \multirow[b]{3}{*}{ Fes } & \multirow[b]{3}{*}{$\mathrm{Cr}_{2} \mathrm{O}_{3}$} & MPL & & & & \\
\hline & & & \multicolumn{5}{|c|}{$1350^{\circ} \mathrm{C}$} \\
\hline & & & 1 & 2 & 3 & 4 & 5 \\
\hline OK & 0 & 50 & 0 & 40 & 27 & 20 & 0 \\
\hline CrK & 1 & 50 & 9 & 12 & 6 & 3 & 7 \\
\hline $\mathrm{Fe}$ & 46 & 0 & 22 & 9 & 7 & 2 & 4 \\
\hline SK & 53 & 0 & 69 & 39 & 60 & 75 & 89 \\
\hline
\end{tabular}

\section{CONCLUSION}

It was observed from $1200{ }^{\circ} \mathrm{C}$, the product of both refractories towards matte showed a significant volume expansion. The matte-refractory interaction can be seen when the temperature is above $1350{ }^{\circ} \mathrm{C}$ where new phases of different elemental composition evolve.

\section{ACKNOWLEDGMENT}

I would like to thank University Of Johannesburg (Dr Kanyane Mpilo, Prof Antoine F. Mulaba-Bafuiandi) for the opportunity that was granted to me and for supplying the materials needed to complete the work.

\section{REFERENCES}

[1] Jacobs, M. 2006. Process description and abbreviated history of Anglo Platinum's Waterval Smelter. Southern African Pyrometallurgy, Cradle of Humankind, South Africa, 5-8 March 2006. Jones, R. (ed.). Southern African Institute of Mining and Metallurgy, Johannesburg, 17-28.
[2] Engel, R. 2010. Chrome bearing Refractories: Is there a Future. The Refractory Engineer, 12-14.

[3] Lange, M., Cromarty, R. \& Garbers-Craig, A.M.. 2014. Wear of Magnesia Chrome Refractory Bricks as a Function of Matte Temperature. Journal of the Southern African Institute of Mining and Metallurgy, 114(4):341-346.

[4] Nelson, L.R. Donald, J., \& Shonelville, R. 2005. Role of Technical Innovation on Production Delivery at the Polokwane Smelter,(Nickel and Cobalt 2005: Challenges in Extraction and Production,Preceedings of the International Symposium on Nickel and Cobalt, 91-116.[21-24 August 2005]

[5] Snyders, C., Eksteen, J., \& Moshokwa, A. 2006. The Polokwane Smelter matte tapping channel model. Fifth International Conference on CFD in the Process Industries, Melbourne, 423-429.

[6] Eksteen, J. 2011. A mechanistic model to predict matte temperatures during the smelting of UG2-rich blends of platinum group metal concentrates. Minerals Engineering,24:676-687. https://doi.org/10.1016/j.mineng.2010.10.017

[7] Thethwayo, B.M., \& Garbers-Craig, A.M. 2011. Laboratory Scale Investigation Into The Corrosion of Copper in a Sulphur-Containing Environment, Corrosion Science, 53:3068-3074. https://doi.org/10.1016/j.corsci.2011.05.016

[8] Thethwayo,B.M. 2010. Sulphidation of Copper Coolers in PGM smelters. MSc Thesis, University Of Pretoria.

[9] Georgalli, G.A., Eksteen, J.J., Nilsson, J.P., Bloewer, P., \& Lyons, A. 2009. Implementation of alternative matte level measurement solution at Lonmin Marikana Smelter Division for Improved process monitoring. Southern African Pyrometallurgy 2011. Johannesburg. The southern African institute of mining and metallurgy, ed. R.T Jones, \& P den Hoed, 269-284.

[10] Du Toit, J., Cromarty, R.D. and Garbers-Craig, A.M., 2016. Matte-tap-hole clay-refractory brick interaction in a PGM smelter. Journal of the Southern African Institute of Mining and Metallurgy, 116(4), pp.339-342. https://doi.org/10.17159/2411-9717/2016/v116n4a6

[11] Thethwayo, B.M. and Cromarty, R.D., 2015. Wettability of graphite by synthetic and industrial PGM-furnace matte. Cerâmica, 61(358), pp.219-223 https://doi.org/10.1590/0366-69132015613581883

[12] Thethwayo, B.M., 2019. Interaction of carbon-based refractories with liquid PGM-furnace melt (Doctoral dissertation, University of Pretoria). 